\title{
The role of digestive surfactants in determining bioavailability of sediment-bound hydrophobic organic contaminants to 2 deposit-feeding polychaetes
}

\author{
Michael J. Ahrens* , Jonathan Hertz, Elizabeth M. Lamoureux, Glenn R. Lopez, \\ Anne E. McElroy, Bruce J. Brownawell
}

Marine Sciences Research Center, State University of New York, Stony Brook, New York 11794-5000, USA

\begin{abstract}
Solubilization of sediment-bound hydrophobic contaminants (HOCs) by gut fluids of deposit-feeding polychaetes greatly exceeds solubilization by seawater. We present evidence that digestive surfactants exert a central role in HOC desorption, and that the degree of in vitro solubilization by gut fluids is an excellent predictor of HOC absorption efficiency (AE) by the respective worm species. We compared in vitro solubilization of sediment-bound ${ }^{14} \mathrm{C}$-hexachlorobenzene $(\mathrm{HCB})$ and ${ }^{14} \mathrm{C}$-tetrachlorobiphenyl (TCBP) by gut fluids of 2 deposit-feeding polychaete species, Nereis (Neanthes) succinea and Pectinaria (Cistenides) gouldii, to AEs measured in live worms by pulsechase methodology. N. succinea desorbed $72 \%$ HCB and $79 \%$ TCBP in vitro (during 6 h incubations), and absorbed both compounds with $73 \%$ efficiency, while $P$. gouldii desorbed only $37 \%$ HCB in 6 h, and analogously absorbed only $37 \%$ HCB. Higher desorption and absorption efficiencies of N. suCcinea were accompanied by greater gut-fluid surfactancy and higher micelle concentration (determined by drop contact angle) compared to $P$. gouldii. Calibration of desorption efficiencies with a synthetic surfactant, sodium dodecyl sulfate (SDS), showed that $N$. succinea gut fluid desorbed a similar amount of HOC as a $1 \%$ (ca $3.5 \mathrm{mM}$ ) SDS solution, whereas $P$. gouldii gut fluid was equivalent to a $0.25 \%$ (ca $0.9 \mathrm{mM}$ ) SDS solution. Detailed analysis of the kinetics of HOC desorption (after 1, 45 and $360 \mathrm{~min}$ ) showed that gut fluids from both polychaetes desorbed more than two-thirds of the bioavailable HOC within the first minute, suggesting that digestive desorption occurs rapidly and that gutresidence time has only minor influence on the degree of desorption or absorption of sediment-bound HOCs.
\end{abstract}

KEY WORDS: Deposit feeding $\cdot$ Organic contaminants $\cdot$ Bioavailability $\cdot$ PCB $\cdot$ Polychaetes $\cdot$ Absorption $\cdot$ Digestion $\cdot$ Surfactants

\section{INTRODUCTION}

Marine sediments have become large repositories for particle-reactive trace metals and hydrophobic organic contaminants (HOCs), such as polycyclic aromatic hydrocarbons (PAHs), polychlorinated biphenyls

*Present address: National Institute of Water and Atmospheric Research (NIWA), Gate 10 Silverdale Rd., PO Box 11115, Hamilton, New Zealand. E-mail: m.ahrens@niwa.cri.nz
(PCBs) and other halogenated hydrocarbons. The extent to which these sediment-bound contaminants pose a risk to benthic organisms largely depends on their bioavailability. Deposit-feeding polychaetes are particularly subject to high HOC exposure since they ingest large amounts of sediment (commonly at rates exceeding several times their body weight per day; Cammen 1980) and constitute the dominant macrofauna in muddy environments, which often tend to be depositional centers for organic matter and contaminants (Jumars et al. 1990). Despite considerable pro- 
gress in understanding sediment-contaminant interactions, one of the remaining uncertainties continues to be the degree to which contaminants are absorbed from food and assimilated into animal tissues (Penry 1998, Wang \& Fisher 1999). Absorption efficiencies (AEs), i.e. the percentage of contaminants that are retained in an organism per gut filling, can vary from a few to over $90 \%$ for different contaminants and different animal species. Hypotheses on what influences absorption efficiency (also termed bioavailability) range from characteristics of the sediment (organic carbon content, mineralogy, surface area, redox condition and sediment age) to characteristics of the organism's feeding physiology (ingestion rate, gut passage time and digestive chemistry; Standley 1997). However, one underlying assumption is that digestive uptake proceeds via a mobile (i.e. truly dissolved or colloidal) phase, so that sediment-bound compounds require prior solubilization in order to be absorbed (DiToro et al. 1991, Wang \& Fisher 1999).

Can characteristics of an organism's digestive chemistry be used to predict dietary uptake, i.e. absorption efficiency? Mayer et al. (1996) showed that digestive fluids of the lugworm Arenicola marina and the holothuroid Parastichopus californicus solubilized up to 200 times more PAHs and up to 2400 times more copper than did seawater, concluding that (2-phase) seawater-solid partitioning models may greatly underestimate bioavailability. In ensuing work, Weston \& Mayer $(1998 \mathrm{a}, \mathrm{b})$ demonstrated that A. marina absorbed benzo(a)pyrene (BaP) with efficiencies (27 to $55 \%$ ) that were comparable to those desorbed by gut fluids in vitro (13 to $52 \%$ ). This led them to conclude that solubilization of sediment-bound contaminants during gut passage is critical for subsequent uptake and, furthermore, that nearly all of that solubilized during digestion is ultimately absorbed. As a caveat, the sediments used by Weston \& Mayer $(1998 a, b)$ were exclusively sandy $(<16 \%$ silt and clay) and low in organic carbon (0.06 to $1.4 \%$ ), which is quite uncharacteristic of many contaminated harbor sediments that tend to be more organic carbon-rich and muddy.

Digestive surfactants have recently come under scrutiny as likely causes for the greater HOC solubilizing power of gut fluids as compared to seawater. Surfactants occur in high concentrations in the digestive tracts of deposit feeding organisms (Mayer et al. 1997), and although their function and composition are practically unknown, it is conjectured that they aid in the digestive process either by solubilizing hydrophobic food material or by inhibiting adsorptive loss of digestive enzymes and dissolved organic matter (DOM) onto sediment particles. Although digestive surfactants have been suspected to facilitate HOC solubilization for some time, only recently, Voparil \& Mayer (2000) show evidence that micellar surfactant phases and not other DOM are the dominant and most effective solubilizers of PAHs in gut fluids of Arenicola marina. The biphasic pattern of PAH solubilization they observed (characterized by a rapid increase of desorption above the critical micellar dilution, CMD, measured by gut-fluid contact angles) strongly implicated surfactant micelles as chief solubilizers, although at high enough concentrations, globular proteins also showed solubilizing properties.

In this paper, we elucidate the role of digestive surfactants in determining bioavailability of chlorinated HOCs to deposit feeders, as part of a comprehensive effort to delineate the factors affecting absorption of sediment-bound contaminants. We expanded Weston \& Mayer's (1998a,b) in vitro solubilization (biomimetic) approach, applied so far only to large sand-feeding deposit feeders, to smaller, mud-feeding deposit feeders and more organic carbon-rich sediment. We chose to work with polychlorinated hydrocarbons (PCBs and chlorobenzenes), which are similarly hydrophobic and ubiquitous, yet much more slowly metabolized and usually more bioavailable than PAHs (which often tend to be strongly adsorbed to soot phases; McGroddy et al. 1996). We compared in vitro gut-fluid solubilization and absorption efficiencies of tetrachlorobiphenyl (TCBP)- and hexachlorobenzene (HCB)-spiked muddy coastal sediments. We tested the hypothesis that deposit feeders absorb these 2 HOCs with similar efficiencies as they are solubilized by their gut fluids, and that the surfactant properties of the gut fluids are the primary factor responsible for their solubilization.

\section{MATERIALS AND METHODS}

Sediment collection. Sediment for all experiments was collected from Flax Pond, a salt marsh bordering Long Island Sound, New York, during September 1997. Sediment was collected at low tide, using polypropylene core tubes to retain the loose surface layer. A $0.5 \mathrm{~cm}$-thick layer was carefully scooped off the surface and rinsed through a $300 \mu \mathrm{m}$ sieve using Flax Pond seawater (FPSW, salinity ca $28 \mathrm{ppt}$ ), to remove macrofauna and coarse debris (pebbles and Spartina alterniflora stalks). The $<300 \mu \mathrm{m}$ fraction was retained for the ensuing experiments and refrigerated $\left(+1^{\circ} \mathrm{C}\right)$ until use.

Sediment characteristics. Flax Pond sediment has been characterized by Montluçon (1997), who conducted a 20 mo sedimentological survey from 1995 to 1997 at the same location as sampled by us. The top $10 \mathrm{~cm}$ sediment layer consists of 25 to $44 \%$ sand (>64 $\mu \mathrm{m}), 41$ to $61 \%$ silt ( 4 to $64 \mu \mathrm{m}$ ), and 11 to $24 \%$ clay $(<4 \mu \mathrm{m})$. Surface area, measured by the singlepoint mitrogen adsorption method (described by Mayer et al. 1988), ranged between 6.8 to $10.0 \mathrm{~m}^{2} \mathrm{~g}^{-2}$, 
with an organic carbon content of 2.1 to $3.1 \%$ of sediment dry weight (see also Yamamoto \& Lopez 1985). While monitoring Flax Pond sediment characteristics over the course of 20 mo, Montluçon (1997) found no significant seasonally related variability in sediment grain size, surface area or carbon content. The water content of the surface sediment was approx. $52 \%$ (Ahrens unpubl. data).

Sediment labeling. For absorption efficiency as well as desorption experiments, we used $430 \mathrm{~d}$ old radioactively labeled sediments, spiked 14 mo previously for a separate study that will be reported elsewhere (Ahrens et al. unpubl. data). Sediments had been radiolabeled with ${ }^{14} \mathrm{C}-2,2$ ' $, 4,4^{\prime}$ tetrachlorobiphenyl (TCBP, PCB congener 47 ); sp. activity $0.385 \mathrm{MBq} \mu \mathrm{mol}^{-1}$, and ${ }^{14} \mathrm{C}$-hexachlorobenzene (HCB); sp. activity $0.392 \mathrm{MBq} \mu \mathrm{mol}^{-1}$, employing the slurry method of McElroy \& Means (1988). Two $5 \mathrm{ml}$ batches of settled $(<300 \mu \mathrm{m}$ sieved) sediment were placed in glass containers, and 1 batch was spiked with $0.062 \mathrm{MBq}$ of ${ }^{14} \mathrm{C}$-TCBP, while the other was spiked with $0.044 \mathrm{MBq}$ of ${ }^{14} \mathrm{C}-\mathrm{HCB}$, to render final ${ }^{14} \mathrm{C}$ activities of $0.012 \mathrm{MBq} \mathrm{ml}{ }^{-1}$ (TCBP) and $0.009 \mathrm{MBq} \mathrm{ml}^{-1}$ (HCB) respectively. This corresponded to HOC sediment concentrations of approximately $32 \mathrm{nmol} \mathrm{m}^{-1}\left(68 \mathrm{nmol} \mathrm{g}^{-1}\right)$ for TCBP and $22 \mathrm{nmol} \mathrm{ml}^{-1}$ $\left(47 \mathrm{nmol} \mathrm{g}^{-1}\right)$ for HCB on a volume or dry weight basis, respectively. After spiking, jars were placed on an orbital shaker at room temperature $\left(24^{\circ} \mathrm{C}\right)$ for $1 \mathrm{~d}$ to thoroughly homogenize the labeled sediments. Sediments were aged in brown glass containers in a refrigerator $\left(+1^{\circ} \mathrm{C}\right)$ for $430 \mathrm{~d}$ before conducting the absorption and desorption experiments. Microbial degradation of the labeled HOCs during this time period was presumed to be negligible, since PCBs and hexachlorobenzene are very resistant to metabolic breakdown (Schwarzenbach et al. 1993).

Absorption efficiency experiments. Animal collection and maintenance: The species investigated were Nereis (Neanthes) succinea and Pectinaria (Cistenides) gouldii, 2 abundant and widely distributed depositfeeding polychaete species in temperate nearshore sediments. N. succinea is a surface deposit feeder, while $P$. gouldii is a head-down deposit feeder (Fauchald \& Jumars 1979).

Nereis succinea (5 to $10 \mathrm{~cm}$ body length) were collected from Flax Pond, Long Island, New York in July 1999 by hand and shovel. The worms were immediately isolated in the laboratory to prevent aggressive interactions. N. succinea were maintained in feeding chambers constructed from two $100 \mathrm{ml}$ polypropylene vials connected by a U-shaped piece of Tygon tubing (i.d. $=3.2 \mathrm{~mm}$ ), and a second piece of Tygon tubing serving to equilibrate water level differences (Fig. 1a), analogous to the chambers of Wang et al. (1999). Jars were filled with FPSW and kept devoid of sediment except for food. Only actively feeding and defecating worms were used for the ensuing absorption efficiency experiments.

Pectinaria gouldii (2 to $3 \mathrm{~cm}$ body length) were collected from Great South Bay, Long Island, New York during July 1999. Worms were placed individually and head-first in $100 \mathrm{ml}$ glass jars filled with 30 to $50 \mathrm{ml}$ glass beads (diam. $=360 \pm 50 \mu \mathrm{m}$; Potters Industries, Brownwood, Texas) and 50 to $60 \mathrm{ml}$ FPSW. The worms were fed by injecting sediment to the bottom of the jar using a pipette. The glass beads hereby served the primary function of anchoring the worms in a head-down position. Feces were collected in custom-fitted plastic vials, slipped over the posterior openings of the worms' conical tubes (Fig. 1b). The worms were acclimatized to experimental conditions for several days while being fed on unlabeled Flax Pond surface sediment. As for Nereis succinea, only actively feeding and defecating individuals were used.

Feeding and depuration: Feeding experiments to determine absorption efficiency followed pulse-chase methodology (Lopez \& Cheng 1983, Reinfelder \& Fisher 1991, Luoma et al 1992, Wang et al. 1999, review by Wang \& Fisher 1999). In general, worms were allowed to feed on radiolabeled sediment for a duration shorter than their gut-passage time, whereupon the radiolabeled sediment was removed, and the worms were given unlabeled sediment to depurate their guts of all unabsorbed radioactive material. Fecal matter was collected for each inividual in separate vials. To facilitate the identification and retrieval of radiolabeled feces, non-radioactive sediment was optically labeled with fluorescent pigment (Radiant Color, Magruder Color Company, Elizabeth, New Jersey). Feeding experiments were conducted at $24^{\circ} \mathrm{C}$. Nereis succinea were fed either ${ }^{14} \mathrm{C}$-TCBP- and ${ }^{14} \mathrm{C}$-HCB-spiked sediments, whereas Pectinaria gouldii was fed only ${ }^{14} \mathrm{C}-\mathrm{HCB}-$ labeled sediment. The reason for not feeding ${ }^{14} \mathrm{C}$ TCBP to $P$. gouldii was that we had only limited amounts of ${ }^{14} \mathrm{C}$-TCBP-labeled sediment available at the beginning of the experiment.

Nereis succinea were fed by pipetting a small amount of radiolabeled sediment (less than 1 gut filling) in front of the worms' mouths. Then worms usually initiated feeding within $30 \mathrm{~min}$ of food presentation. After approx. $3 \mathrm{~h}$ feeding (a time period shorter than the minimum gut-residence time in the laboratory), chambers were pipetted clear of all radiolabeled sediment, and unlabeled, fluorescently tagged (pink) sediment was added. Worms were then left to depurate themselves of unabsorbed food for 4 to $24 \mathrm{~h}$, depending on individual performance, and their fecal material was removed upon occurrence. Depuration was considered complete when several strings of pink (nonradioactive) feces were defecated. 


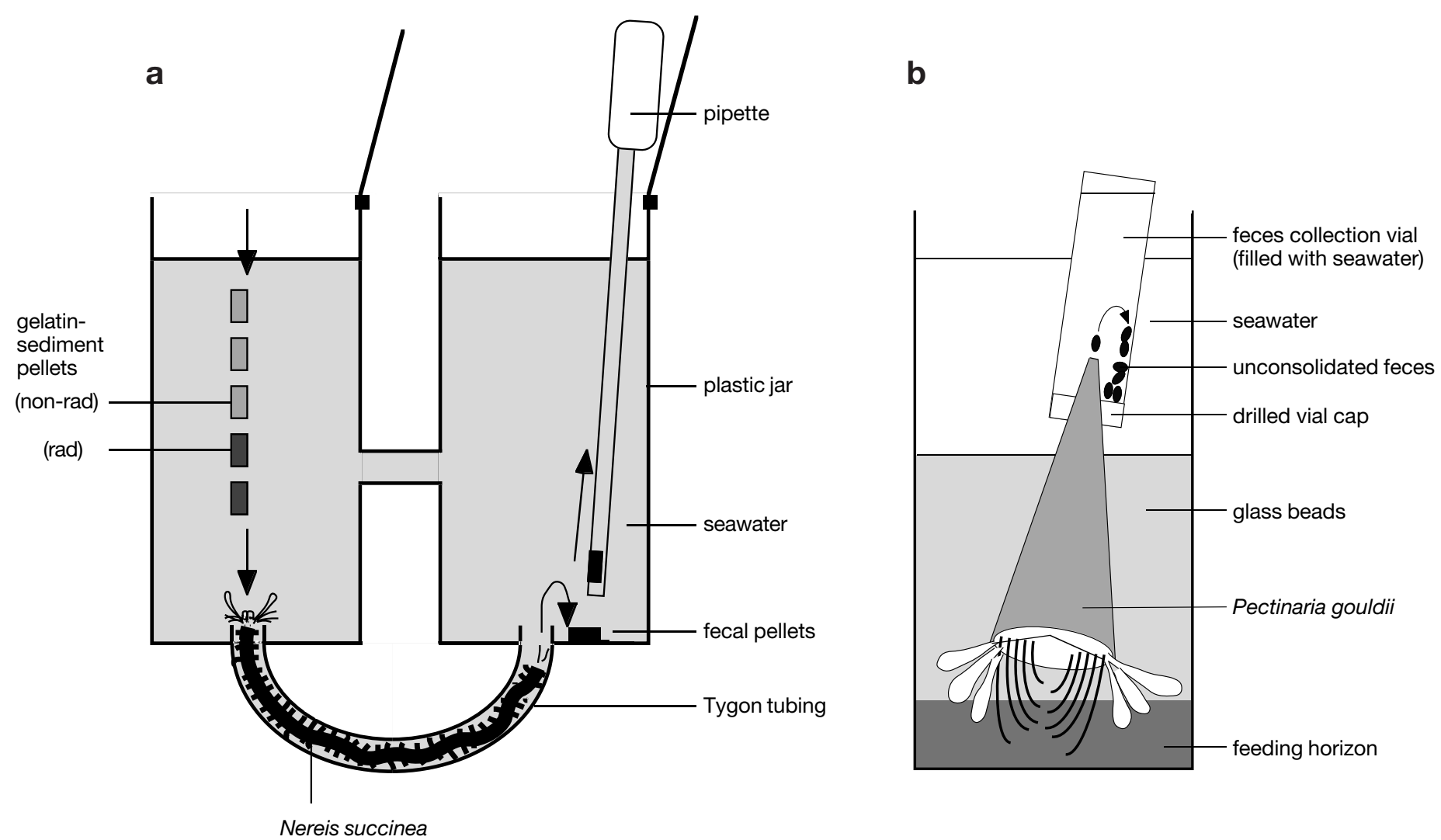

Fig. 1. Feeding chambers for absorption efficiency experiments with (a) Nereis succinea and (b) Pectinaria gouldii. (a) is adapted from Wang et al. (1999). rad: radiolabeled

Pectinaria gouldii were fed by injecting ${ }^{14} \mathrm{C}-\mathrm{HCB}-$ labeled sediment into the bottom layer of their glassbead-filled feeding chambers using a Pasteur pipette. After a minimum feeding period of $2 \mathrm{~h}$, the worms were removed from the radioactive jar, rinsed with FPSW, and placed in a second jar, containing a $0.5 \mathrm{~cm}$ thick bottom layer of non-radioactive, fluorescently tagged (orange) Flax Pond sediment, and covered with glass beads. Since the feces of $P$. gouldii are rather unconsolidated, they were collected in the following way: A $4 \mathrm{ml}$ scintillation vial with a perforated cap was filled with seawater, and slipped over the posterior opening of the worm's conical tube (Fig. 1b). By this procedure, all fecal material produced by a worm was collected in the vial, and was neither diluted nor lost on the sediment surface. Worms were depurated until appearance of the orange (non-radioactive) sediment in the collection vial, for a minimum duration of $3 \mathrm{~h}$.

Sample preparation: After depurating all radiolabeled sediment from their digestive tracts, the worms were removed from their feeding chambers, rinsed, blotted, weighed and frozen at $-20^{\circ} \mathrm{C}$ until further analysis. To check for leaching or excretion of TCBP and HCB into chamber water, $1 \mathrm{ml}$ aliquots were taken at the end of the depuration period and found to con- tain negligible amounts of radioactivity. Feces and worm samples were solubilized using 1 to $2 \mathrm{ml}$ of an alkaline tissue solubilizer (Solvable, Packard), and digested at $60^{\circ} \mathrm{C}$ for a minimum duration of $4 \mathrm{~h}$. Turbid samples were divided among several counting vials. Pectinaria gouldii were removed from their sediment tubes prior to solubilization, and their feces were transferred from the $4 \mathrm{ml}$ collection vials to $20 \mathrm{ml}$ counting vials. In preparation for scintillation counting, 10 to $15 \mathrm{ml}$ cocktail (Ultima Gold XR, Packard) were added to each vial. Blanks received $10 \mathrm{ml}$ cocktail and $1 \mathrm{ml}$ Solvable.

Counting and calculations: Samples were counted for $300 \mathrm{~s}$ on a Wallac LKB 1217 Rackbeta liquid scintillation counter, employing automatic quench correction and background (blank) subtraction. Absorption efficiencies (AE) were calculated according to Eq. (1), assuming a mass balance,

$$
\mathrm{AE}=100 \times \frac{A(\text { retained })}{A(\text { ingested })}=100 \times \frac{A(\text { worm })}{A(\text { worm })+A(\text { feces })}(1)
$$

in which $\mathrm{AE}$ is the absorption efficiency (in \%), $A$ (worm) is the ${ }^{14} \mathrm{C}$ activity (in dpm) of the organism tissue and $A$ (feces) is the ${ }^{14} \mathrm{C}$ activity (in dpm) of the 
feces. The sum of $A($ worm $)+A($ feces $)$ is assumed to approximate the activity ingested, if feces are collected quantitatively and leaching or excretion into surrounding water can be neglected (as was the case in our experiments). Samples with $<4$ times background activity (i.e. $<100 \mathrm{dpm}$ ) were excluded from further analysis. We operationally defined $\mathrm{AE}$ as the percentage of HOC activity retained in the worms after defecation of all radiolabeled sediment. To what extent the AEs determined by this approach truly represented uptake by the worm is addressed in the discussion.

Desorption experiments. To estimate the efficiency and kinetics of solubilization occurring in the worm's intestines, we performed several in vitro desorption experiments with gut fluids collected from live individuals. In brief, the same ${ }^{14} \mathrm{C}$-TCBP- and ${ }^{14} \mathrm{C}$-HCBlabeled sediments as used for the $\mathrm{AE}$ experiments were mixed with Nereis succinea and Pectinaria gouldii gut fluids and agitated mechanically to mimic digestion. FPSW and 5 concentrations of a synthetic surfactant, sodium dododecyl sulfate (SDS), were used as controls and for comparisons of surfactancy. Desorption was measured as the activity in the dissolved phase versus total activity (dissolved + particulate). Because of limited amounts of ${ }^{14} \mathrm{C}$-TCBP-labeled sediment available, desorption experiments with $P$. gouldii gut fluid were only carried out with ${ }^{14} \mathrm{C}$-HCB-labeled sediments.

Gut fluid collection. Adult Nereis succinea (body length 5 to $10 \mathrm{~cm}$ ) were collected from Flax Pond during July and August 1999 by hand and shovel and depurated overnight to facilitate gut fluid collection. Gut fluid was withdrawn from anaesthetized worms $\left(10 \% \mathrm{MgCl}_{2}\right)$, dissected dorsally along the region of the eighth body segment to expose the stomach. A small incision was made into the stomach lining and, while applying gentle pressure on the posterior end of the worm (using the metal handle of a dissection needle), the emerging mahogany-colored fluid was withdrawn using a glass capillary. Gut fluid contaminated with blood (indicated by a red hue) was rejected. On average, $12 \mu \mathrm{l}$ of $N$. succinea fluid was collected per individual. Gut fluid was centrifuged and stored frozen $\left(-20^{\circ} \mathrm{C}\right)$ in $1.5 \mathrm{ml}$ Eppendorf vials until use. Solid/fluid ratios of gut contents were estimated by removing sections of the digestive tracts of 5 worms and determining wet and dry weights respectively.

Pectinaria gouldii (body length 2 to $3 \mathrm{~cm}$ ) were collected during July 1999 from Great South Bay, New York, and maintained in aerated plastic trays with surface sediment until dissection. For gut fluid collection, 100 individuals were anaesthetized in $10 \% \mathrm{MgCl}_{2}$, decapitated and their entire digestive tract withdrawn from the body cavity using a pair of forceps. Adhering blood vessels were removed, and the guts were placed in $1.5 \mathrm{ml}$ Eppendorf vials and centrifuged for 1 to $2 \mathrm{~min}$ at $1000 \times g$ to separate gut fluid from sediment and tissue. The overlying amber-colored fluid was frozen at $-20^{\circ} \mathrm{C}$ until use. Approximately 4 to $5 \mu \mathrm{l}$ of $P$. gouldii gut fluid was collected per individual. The solid/fluid ratios of the gut contents were determined by pooling the excised digestive tracts of several individuals in 1 preweighed vial and measuring wet and dry weight. Gut tissue was a minor component of the particulate fraction.

Surfactancy measurements: The surface tension of digestive fluids was measured by drop contact angle (Mayer et al. 1997). A $1 \mu l$ droplet of gut fluid was pipetted onto a Parafilm ${ }^{\circledR}$-covered glass slide, and viewed sideways using a $45^{\circ}$ inclined first-surface mirror and a video camera attached to a dissecting microscope. The inner angle between the drop and the fluid-repellent Parafilm surface was measured using an image-analysis program (National Intistute of Health image). This angle was termed the fluid's contact angle. Care was taken to measure the contact angle immediately after placing the drop onto the Parafilm surface, to minimize evaporation of gut fluid, which could affect the angle. Larger contact-angle values signified greater surface tension and consequently lower surfactancy. Contact angles were determined for Nereis succinea and Pectinaria gouldii gut fluid, sodium dodecyl sulfate (SDS) in seawater, and $0.2 \mu \mathrm{m}$-filtered FPSW. We furthermore determined the critical micelle dilution (CMD) of each fluid, i.e. the dilution at which surfactant molecules are no longer present as micelle clusters but entirely as dispersed, single molecules. For this, we prepared progressive seawater dilutions of gut fluids and SDS respectively, and determined each fluid's contact angle, from full strength down to a final dilution of $1 \%$ for gut fluids and $0.001 \%(=3.5 \mu \mathrm{M})$ for SDS. The CMD was defined as the threshold dilution after which further dilution caused a rapid increase of the fluid's contact angle. In addition to surfactancy measurements, gut fluid $\mathrm{pH}$ was measured using a microelectrode (MI-413, Microelecrodes Inc.), and $\mathrm{C}$ and $\mathrm{N}$ were determined using a CNS analyzer (Carlo-Erba EA1100) after prior dehydration $\left(50^{\circ} \mathrm{C}\right)$ of the gut fluid.

Sediment extraction: Approximately 50 to $150 \mu \mathrm{l}$ of either ${ }^{14} \mathrm{C}$-TCBP- or ${ }^{14} \mathrm{C}$-HCB-labeled sediment slurry were pipetted into pre-weighed $1.5 \mathrm{ml}$ glass centrifugation vials and centrifuged $(1600 \times g$ for $4 \mathrm{~min})$ to render an average wet sediment weight of $30 \mathrm{mg}$ (corresponding to approx. $14.4 \mathrm{mg}$ dry sediment weight). Four extraction agents were used: Nereis succinea gut fluid, Pectinaria gouldii gut fluid (only for ${ }^{14} \mathrm{C}-\mathrm{HCB}-$ labeled sediment), FPSW ( $<0.2 \mu \mathrm{m}$-filtered) and 5 dilutions of SDS in seawater $(0.1,0.25,0.5,0.8$, and $1.0 \%$ by weight, corresponding to $0.35,0.87,1.7,2.8$ and 3.5 $\mathrm{mM})$. A total of $150 \mu \mathrm{l}$ of each agent were added to 30 mg wet sediment, which corresponded to a solid/fluid 
ratio of $0.1 \mathrm{~g} \mathrm{ml}^{-1}$ on a dry sediment basis. Vials were vortexed for $10 \mathrm{~s}$ and placed on an orbital shaker at lowest setting (Fisher Vortex Genie 2). Extractions were conducted for 3 different durations: 1,45 , and $360 \mathrm{~min}$, in separate vials. At the end of the designated extraction interval, $500 \mu \mathrm{l}$ of seawater $(<0.2 \mu \mathrm{m}$ filtered) were added to the vial and vortexed. This served to increase the fluid volume and rinse out gut fluid or surfactant contained in pore waters. The vial was then centrifuged at $1000 \times g$ for $1 \mathrm{~min}$, after which the overlying (termed 'dissolved') fraction was removed into a $20 \mathrm{ml}$ glass scintillation vial with a Pasteur pipette. The rinse and centrifugation cycle was repeated 2 more times ( $500 \mu \mathrm{l}$ seawater per cycle), and the overlying ('dissolved') fractions of the 3 rinses were pooled in one $20 \mathrm{ml}$ scintillation vial. Utmost care was taken to avoid resuspension of sediment while withdrawing the dissolved fraction. After completion of the 3 rinse cycles, the remaining particulate fraction was resuspended in $500 \mu \mathrm{l}$ Solvable (Packard) and transferred into a separate scintillation vial. Particles remaining in the extraction vial were rinsed out with $500 \mu \mathrm{l}$ seawater and added to the particulate fraction. Treatments were staggered at 5 min intervals to allow for adequate handling time.

Sample preparation and counting: $15 \mathrm{ml}$ Ultima Gold XR scintillation cocktail were added to dissolved and particulate samples respectively. Blanks were prepared from $0.5 \mathrm{ml}$ seawater and $15 \mathrm{ml}$ scintillation cocktail. Samples were counted for $300 \mathrm{~s}$ on a Wallac LKB 1217 Rackbeta liquid scintillation counter, identical to the AE experiments described above. Desorption efficiency (DE) was calculated as the percentage of radioactivity in the dissolved phase divided by total radioactivity (dissolved + particulate), according to Eq. (2):

$$
\mathrm{DE}=100 \times \frac{A(\text { dissolved })}{A(\text { dissolved })+A(\text { particulate })}
$$

Repetitive addition experiment: To elucidate to what degree desorption is limited by the volume of extraction agent, we conducted an experiment in which we repeatedly added small amounts of gut fluid to the same sediment sample and measured the amount of activity desorbed by each addition. This experiment was conducted using only ${ }^{14} \mathrm{C}$-TCBP-labeled sediment. As in previous desorption experiments, $30 \mathrm{mg}$ of ${ }^{14} \mathrm{C}$ TCBP-labeled sediment were concentrated in $1.5 \mathrm{ml}$ glass vials by centrifugation $(1 \mathrm{~min}$ at $1600 \times g)$. At the start of the experiment, $15 \mu \mathrm{l}$ of extraction agent (either Nereis succinea gut fluid, SDS [5 different concentrations: $0.1,0.25,0.5,0.8$, and $1.0 \%$ by weight in seawater], or FPSW) were added to the vial, and vortexed for $10 \mathrm{~s}$ to mix contents thoroughly. This corresponded to a (dry) solid/fluid ratio of approximately $1 \mathrm{~g} \mathrm{ml}^{-1}$. The vial was then agitated on an orbital shaker for $60 \mathrm{~s}$, af- ter which $500 \mu \mathrm{l}$ of FPSW (0.2 $\mu \mathrm{m}$-filtered) were added, and the vial vortexed for another $10 \mathrm{~s}$ to flush out concentrated pore waters, followed by centrifugation for $60 \mathrm{~s}$ at $1600 \times g$. After centrifugation, the overlying particle-free fraction (approx. $515 \mu \mathrm{l}$ ) was pipetted into a $4 \mathrm{ml}$ (plastic) scintillation vial, and $15 \mu \mathrm{l}$ of fresh extraction agent was added exactly 5 min after the previous addition. This cycle was repeated 10 times, at intervals of $5 \mathrm{~min}$, for a total duration of $45 \mathrm{~min}$. This rendered a total extraction volume of $10 \times 15 \mu \mathrm{l}=$ $150 \mu \mathrm{l}$, corresponding to the $45 \mathrm{~min}$ endpoint of the one-time $150 \mu \mathrm{l}$ addition described earlier. After the last extraction, the particulate fraction remaining in the extraction vial was rinsed into a scintillation vial with $500 \mu \mathrm{l}$ Solvable and 3 rinses $(500 \mu \mathrm{l}$ each) of FPSW. All vials received $3 \mathrm{ml}$ of scintillation cocktail (Packard Ultima Gold XR) and were counted as described above. Blanks were prepared from $0.5 \mathrm{ml}$ FPSW and $3 \mathrm{ml}$ scintillation cocktail. DE at a given time point was calculated as the cumulative percentage of radioactivity in the dissolved phase at that time, divided by the total radioactivity (sum of all dissolved fractions + particulate fraction), according to Eq. (3):

$$
\begin{aligned}
\mathrm{DE}_{n} & =100 \times \frac{\sum_{i=0}^{n} A(\text { dissolved })}{\sum_{i=0}^{45} A(\text { dissolved })+A(\text { particulate })} \\
n & =\{0.5 .10 \ldots 45 \mathrm{~min}\}
\end{aligned}
$$

where $\mathrm{DE}_{n}$ is desorption efficiency (in \%) at time point $n$, and the summation signs represent either the cumulative dissolved activity at time point $n$, or total activity; all other symbols are the same as in Eq. (2).

\section{RESULTS}

\section{Gut fluid characteristics}

Table 1 summarizes several properties of Nereis succinea and Pectinaria gouldii gut fluids. N. succinea gut fluid was dark brown and slightly acidic (pH 6.88), with the lowest contact angle $\left(36^{\circ}\right)$ of all fluids measured. In contrast, FPSW had a pH of 7.81 and a contact angle of $89^{\circ}$, while SDS ( $1 \%$ by weight, or $3.5 \mathrm{mM}$ ) had a $\mathrm{pH}$ of 7.79 and a contact angle of $48^{\circ}$. P. gouldii gut fluid was amber-colored, with a $\mathrm{pH}$ of 6.74 and a contact angle of $60^{\circ}$. N. succinea and P. gouldii gut fluid both displayed micelle-like properties, yet $N$. succinea gut fluid could be diluted 10-fold before reaching its CMC, compared to roughly 2 -fold for $P$. gouldii, suggesting a higher micelle concentration for $N$. succinea. $N$. succinea gut fluid also had 4 to 5 times higher $\mathrm{C}$ and $\mathrm{N}$ concentra- 
Table 1. Characterization of extractants used for desorption experiments. avg. \pm SD; nd: not determined; (n) number of worms from which fluid was pooled; calcul.: calculated

\begin{tabular}{|c|c|c|c|c|c|c|c|c|}
\hline Fluid & $\begin{array}{l}\text { Contact } \\
\text { angle } \\
\left(^{\circ}\right)\end{array}$ & $\begin{array}{l}\text { Critical } \\
\text { micelle } \\
\text { dilution }\end{array}$ & $\mathrm{pH}$ & $\begin{array}{c}\mathrm{N} \\
\left(\mathrm{mg} \mathrm{ml}^{-1}\right)\end{array}$ & $\begin{array}{c}\mathrm{C} \\
\left(\mathrm{mg} \mathrm{ml}^{-1}\right)\end{array}$ & Color & $\begin{array}{c}\text { Gut (dry) } \\
\text { solid/fluid ratio } \\
\left(\mathrm{mg} \mathrm{mg}^{-1}\right)\end{array}$ & $\begin{array}{l}\text { Gut juice } \\
\text { per worm } \\
\left(\mu l \text { ind }^{-1}\right)\end{array}$ \\
\hline $\begin{array}{l}\text { Nereis (Neanthes) succinea } \\
\text { gut fluid }(\mathrm{n}=14)\end{array}$ & $36 \pm 4$ & $10 \%$ & 6.88 & $11.1 \pm 0.8$ & $70.8 \pm 4.8$ & $\begin{array}{c}\text { Dark } \\
\text { brown }\end{array}$ & $0.48 \pm 0.22$ & $\sim 12$ \\
\hline $\begin{array}{l}\text { Pectinaria (Cistenides) gouldii } \\
\text { gut fluid }(\mathrm{n}=100)\end{array}$ & $60 \pm 6$ & $40 \%$ & 6.74 & $2.63 \pm 0.03$ & $14.6 \pm 0.2$ & Amber & 0.57 & $\sim 4$ \\
\hline $\begin{array}{l}\mathrm{SDS}\left(\mathrm{C}_{12} \mathrm{H}_{25} \mathrm{OSO}_{3} \mathrm{Na}\right) \\
\quad(1 \% \text { by wt } \approx 3.5 \mathrm{mM} \text { in seawater })\end{array}$ & $48 \pm 4$ & $\begin{array}{l}0.1 \%(\mathrm{wt}) \\
\approx 0.35 \mathrm{mM}\end{array}$ & $7.79 \pm 0.02$ & $\begin{array}{c}0 \\
\text { (calcul.) }\end{array}$ & $\begin{array}{c}5.0 \\
\text { (calcul.) }\end{array}$ & Colorless & & \\
\hline Flax Pond seawater & $89 \pm 2$ & & $7.81 \pm 0.03$ & nd & nd & Colorless & & \\
\hline
\end{tabular}

tions than $P$. gouldii gut fluid: as determined by elemental analysis, $N$. succinea gut fluid contained approx. $11 \mathrm{mg} \mathrm{ml}^{-1}$ nitrogen (P. gouldii $2.6 \mathrm{mg} \mathrm{ml}^{-1}$ ) and $71 \mathrm{mg} \mathrm{ml}^{-1}$ carbon ( $P$. gouldii $14.6 \mathrm{mg} \mathrm{ml}^{-1}$ ). SDS contact angles remained unchanged until a dilution of approx. $0.1 \%$ (by weight), or $0.35 \mathrm{mM}$.

\section{Absorption efficiency}

Absorption and desorption efficiencies are summarized in Table 2. Nereis succinea absorbed TCBP with an efficiency of $72.8 \pm 3.3 \%$ (average \pm SD), and HCB with an efficiency of $72.5 \pm 4.6 \%$ (Figs. $2 b \& 3 b$ ). Dif-

Table 2. Nereis succinea and Pectinaria gouldii. Summary of assimilation and desorption data. nd: not determined; s/f: solid/fluid ratio. Note different solid fluid ratio for SDS in HCB than in TCBP

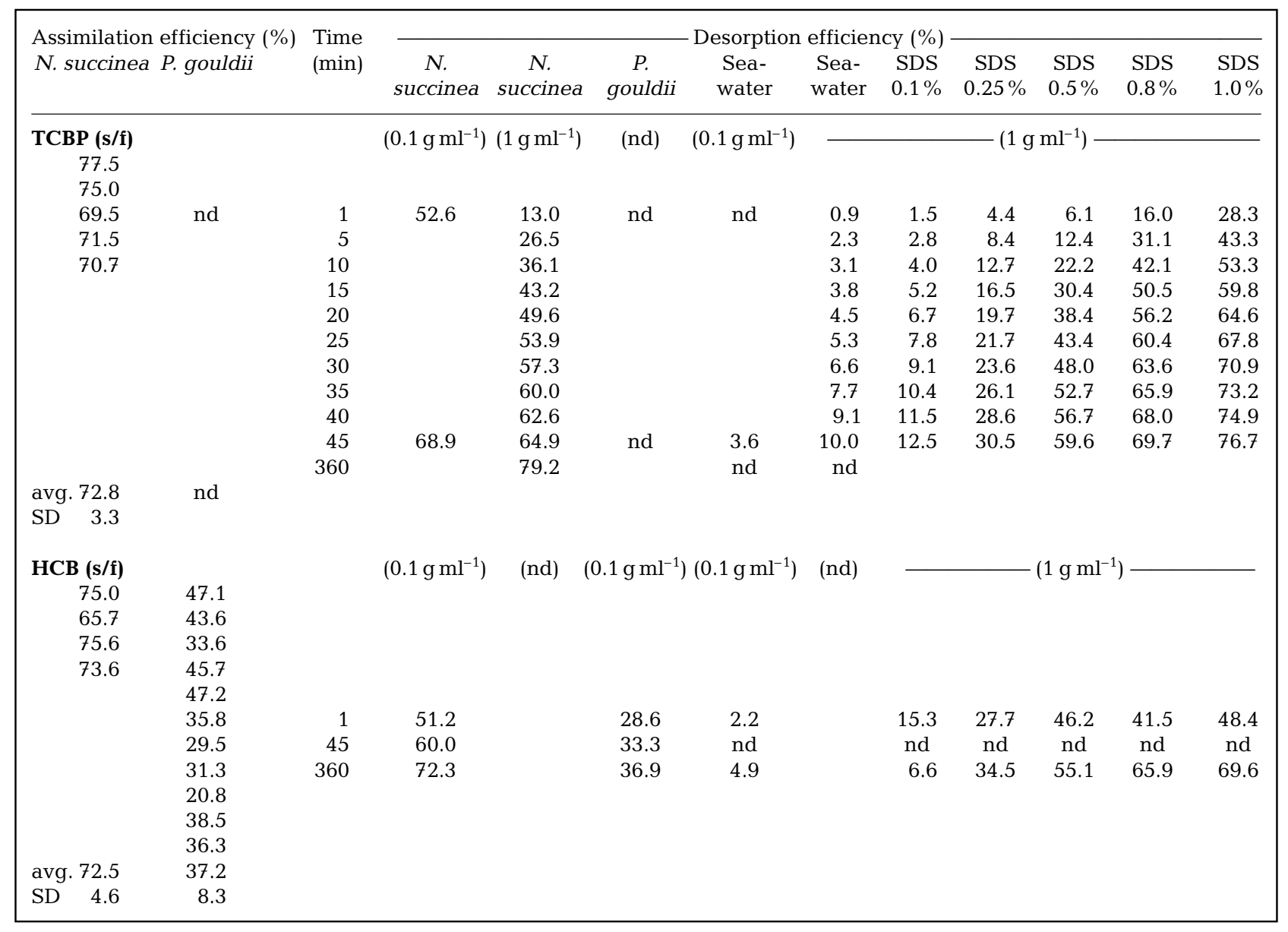


TCBP desorption efficiency

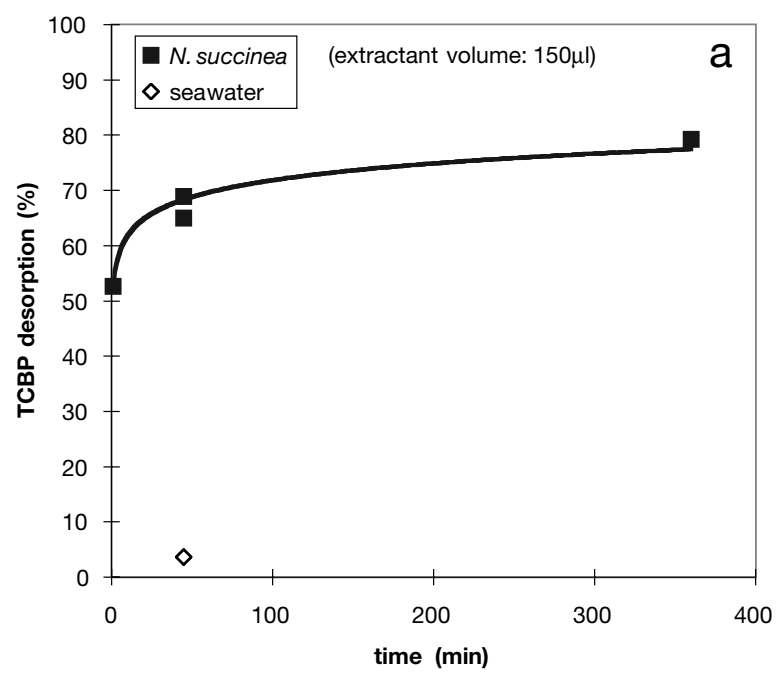

Fig. 2. Nereis succinea. TCBP desorption and absorption efficiency (AE). (a) In vitro desorption kinetics for 1,45 and 360 min extraction durations (30 mg sediment/150 $\mu \mathrm{l}$ extractant); (b) AE determined in feeding experiments $(\mathrm{n}=5)$

ferences in $\mathrm{AE}$ for the $2 \mathrm{HOCs}$ were not statistically significant (Student's $t$-test, 2-tailed, $\mathrm{p}=0.89$ ). In contrast, Pectinaria gouldii absorbed HCB with an efficiency of only $37.2 \pm 8.3 \%$ (Fig. $3 b$ ), which was significantly lower than $N$. succinea's AE for the same compound (Student's $t$-test, 2-tailed, $\mathrm{p}<0.01$ ). AEs for TCBP were not measured for $P$. gouldii due to scarcity of sediment. AE for TCBP and HCB was astoundingly

HCB desorption efficiency

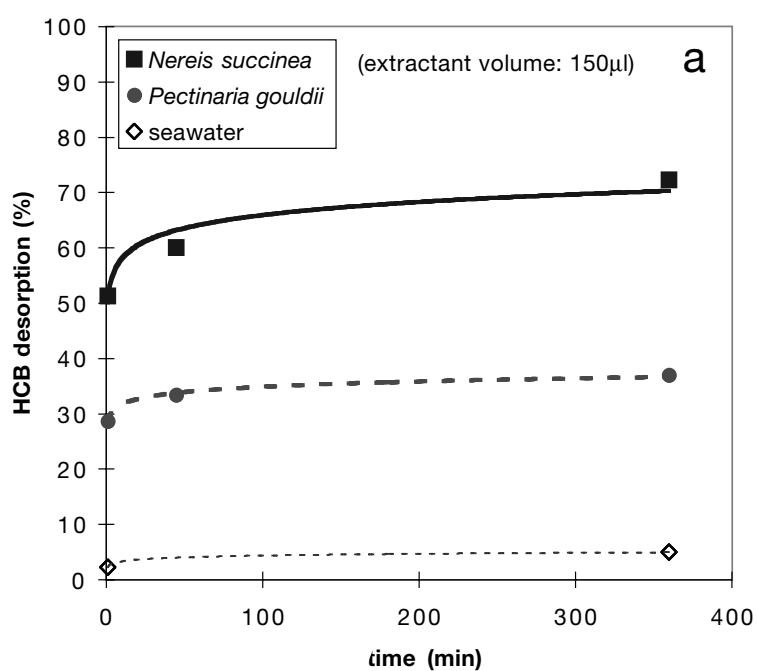

Fig. 3. Nereis succinea and Pectinaria gouldii. HCB desorption and absorption efficiency. (a) In vitro desorption kinetics for 1, 45 and 360 min extraction durations $(30 \mathrm{mg}$ sediment/150 $\mathrm{\mu l}$ extractant); (b) AE determined in feeding experiments $(N$. succinea, $\mathrm{n}=4 ;$ P. gouldii, $\mathrm{n}=11)$ (Fig. 4). Pectinaria gouldii gut fluid desorbed $37 \%$ $\mathrm{HCB}$, considerably less than N. succinea, which corresponded approximately to the DE of a $0.25 \%$ SDS solution (Fig. 4b). The percentages of TCBP and HCB solubilized from sediments (in $360 \mathrm{~min}$ ) were strikingly similar to the respective absorption efficiencies. For instance, $N$. succinea desorbed and absorbed TCBP with $79 \% \mathrm{DE}$ and $73 \% \mathrm{AE}$, and $\mathrm{HCB}$ with $72 \% \mathrm{DE}$ and

$72 \%$ AE. Analogously, P. gouldii desorbed HCB with $37 \%$ DE and absorbed $\mathrm{HCB}$ with $37 \%$ AE. In all 3 cases, HOC desorption efficiency after 360 min was an accurate predictor of AE. It is evident that both HOCs used desorbed to a large extent within the first minute of contact with the digestive fluids (Figs. 2a \& 3a, Table 2), and that only minor further solubilization occurred beyond $45 \mathrm{~min}$.

Results for the repetitive addition experiment (Fig. 5) were quite similar to the results from the 1-time addition experiment, described above. Ten repetitive additions of $15 \mu \mathrm{l}$ Nereis succinea gut fluid desorbed $65 \%$ of TCBP in $45 \mathrm{~min}$, which closely corresponded to the $69 \%$ of TCBP desorbed in $45 \mathrm{~min}$ by a 1 -time addition of $150 \mu \mathrm{l}$ $N$. succinea gut fluid. Differences were observable in the initial time steps of desorption, however. Fig. 5 shows that $15 \mu \mathrm{l} N$. succinea gut fluid desorbed 
only $13 \%$ TCBP in the first minute, in contrast to $53 \%$ for $150 \mu$ l fluid. DE and extraction volume (time) appeared to be related log-linearly. This suggests that under low volume conditions, the solid/fluid ratio may limit the amount of HOC that is desorbable.

\section{DISCUSSION}

DE determined by in vitro gut fluid solubilization was an excellent predictor of HOC AE for Nereis succinea and Pectinaria gouldii. In brief, high surfactancy (low contact angle and low apparent CMD) correlated with high DEs and high AEs for TCBP and HCB. These results strongly implicate digestive surfactants as the likely physiological control of HOC bioavailability. The finding of both lower surface tension and stronger micelle-like properties of $N$. succinea gut fluid compared to those of $P$. gouldii suggests that surfactants in $N$. succinea's gut fluid not only occur at higher concentrations, but probably also have stronger surface-tension altering properties than $P$. gouldii's. The fainter color and 4 to 5 times lower $\mathrm{C}$ and $\mathrm{N}$ content of $P$. gouldii's gut fluid (yet similar $\mathrm{C} / \mathrm{N}$ ratio) further support the conclusion that $P$. gouldii's gut fluid is more dilute. Nonetheless, surfactant concentrations in both species' gut fluids well exceeded their CMD, explaining the much higher DEs compared to seawater. Worm gut fluids displayed similar desorptive strength as mild solutions of the synthetic surfactant SDS ( 0.25 to $1 \%$ by weight) and gut fluid surfactancy appeared to be similarly pH-independent (Ahrens unpubl. data). It has been suggested that invertebrate surfactants are composed of short-chain alkyl groups that are amide or ester bonded to a hydrophilic head group, somewhat similar to the molecular structure of SDS (Vonk 1969, L. Mayer pers. comm.). As a caveat, our conclusion that digestive surfactants are primarily responsible for HOC solubilization is based on correlative evidence only. Thus, other gut fluid parameters that co-vary with surfactancy, such as digestive enzyme and amino acid concentrations, may also play a role in solubilizing hydrophobic substances. In fact, Voparil \&
TCBP-SDS calibration

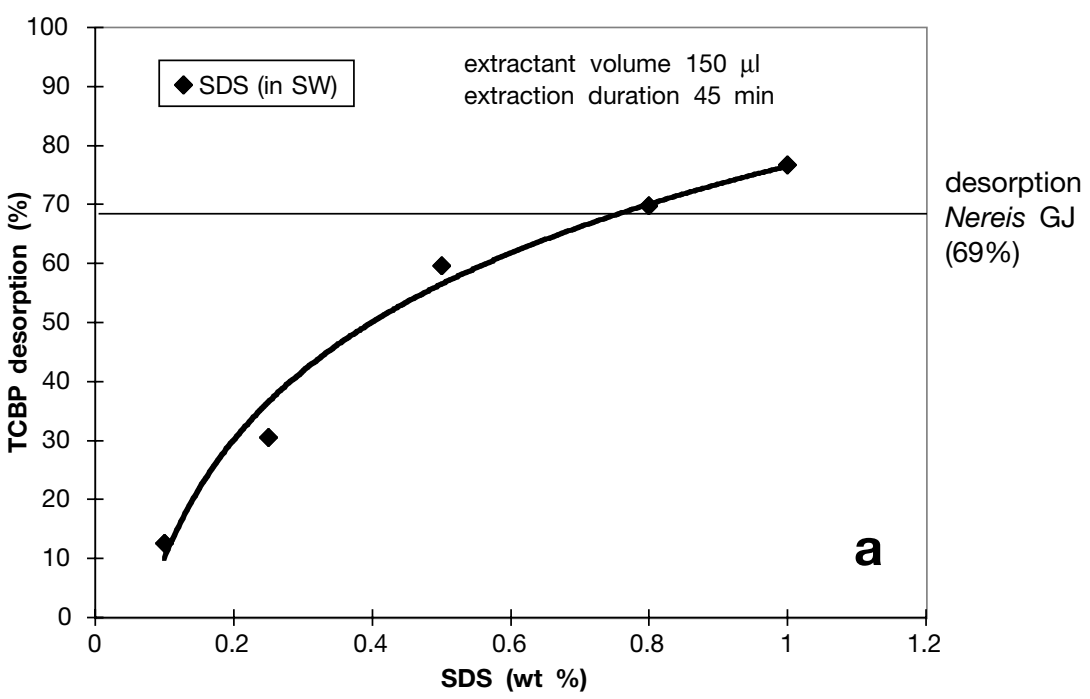

HCB-SDS calibration

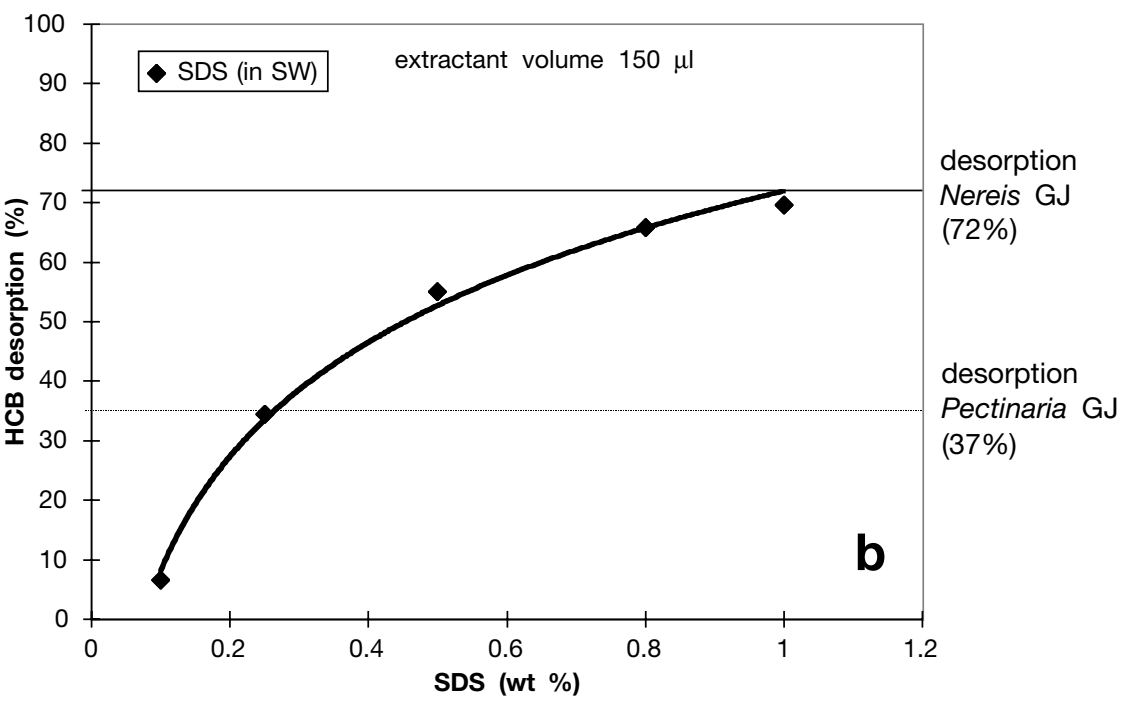

Fig. 4. (a) TCBP solubilization by SDS in seawater, SW (extraction duration $45 \mathrm{~min}$, total extractant volume $150 \mu \mathrm{l}$ ), with desorption efficiency of Nereis succinea gut juice, GJ (45 min extraction) shown for comparison. (b) HCB solubilization by SDS in seawater (extraction duration $360 \mathrm{~min}$, total extractant volume of $150 \mu \mathrm{l}$ ), with desorption efficiency of $N$. succinea and P. gouldii GJ (360 min extraction) shown for comparison

Mayer (2000) recently demonstrated that globular proteins, which make up a large fraction of the gut fluid DOM in deposit-feeding polychaetes, may be responsible for up to half of the benzo(a)pyrene solubilized by gut fluids of Arenicola marina.

The use of a mass balance approach for measuring $\mathrm{AE}$ required the quantitative collection of all fecal material. While this was straightforward for Nereis succinea, owing to its stringy, well-consolidated feces, 


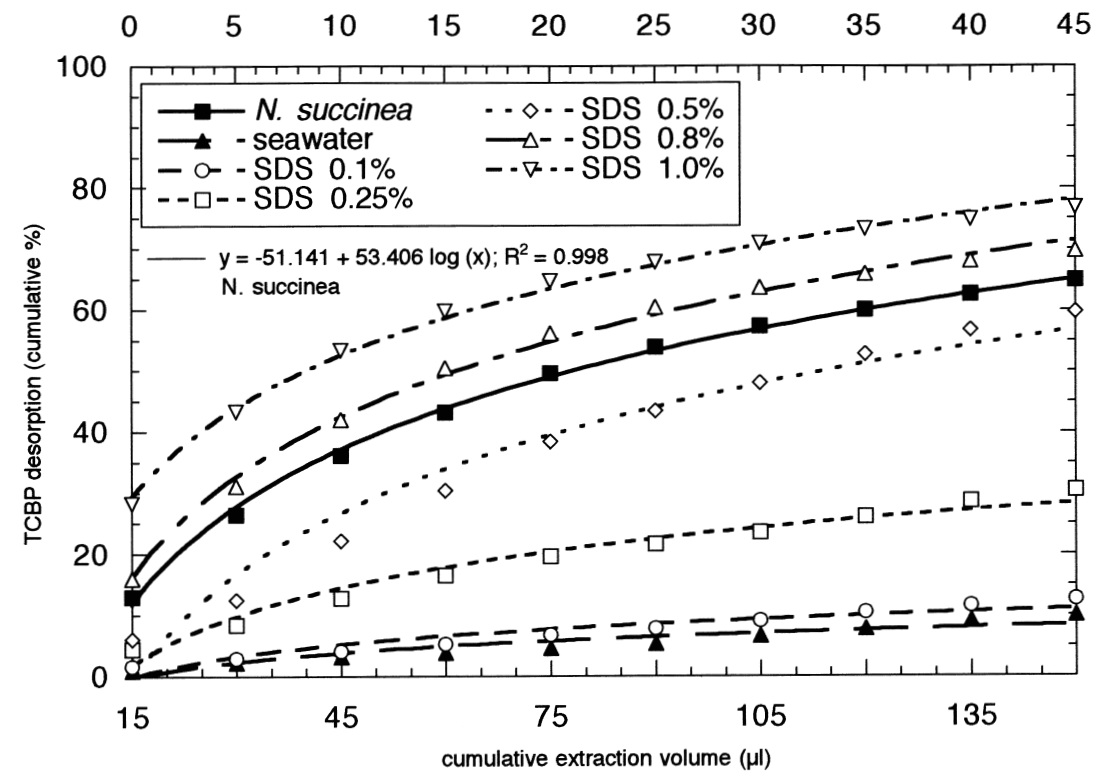

Fig. 5. TCBP solubilization for 10 repetitive extractions of the same sediment sample, as a function of extraction volume (lower axis) or time (upper axis). Ten $15 \mu \mathrm{l}$ aliquots of Nereis succinea gut fluid, seawater or SDS were added to $30 \mathrm{mg}$ sediment in 5 min intervals. Desorption efficiencies (cumulative \%) were loglinearly fitted to extraction volume ( $\mathrm{p}<0.01$ for all plots). Equation shown is for N. succinea gut fluid

the procedure was more involved for Pectinaria gouldii, which defecates only loosely aggregated fecal matter. Slipping a vial over $P$. gouldii's posterior tube opening not only solved the feces collection problem but also improved counting statistics, since the worms could be fed for durations well exceeding their gutpassage time while keeping ingested and defecated material spatially separate. Whitlatch \& Weinberg (1982) verified that sediment collected by this procedure represents truly defecated material and not sediment shunted past the worm and its tube.

Although we operationally defined $\mathrm{AE}$ as the percentage of activity retained by worms after defecation of all ingested radiolabeled sediment, we are aware that this percentage may constitute an upper estimate of $\mathrm{AE}$, since not all activity desorbed from sediments into the gut fluid (and therefore counted as A[worm]) was necessarily absorbed by the gut and assimilated into tissue. Applying the stringent criteria of Penry (1998), we cannot differentiate assimilation from absorption nor digestion, since our mass balance approach gives no information about where inside an organism the measured activity is distributed (e.g. gut fluid, digestive epithelium or entire body tissue). If the solubilized HOC are retained significantly longer in the gut than particulate material (without being ultimately absorbed), our AE values are too high. While we could have verified this by removing particulate as well as fluid gut contents from the worms' digestive tracts before scintillation counting, these dissections proved to be discouragingly complicated for the small-sized worms used. Weston \& Mayer (1998b), using a different approach for estimating $\mathrm{AE}$ (i.e. by comparison of HOC concentrations of gut contents between different regions of the digestive tract), also found PAH absorption to correlate closely with in vitro solubilization in Arenicola marina, concluding that absorption with respect to the desorbed fraction was close to $100 \%$. Conversely, metabolic degradation of HOC during the depuration period could possibly have diminished apparent AEs. However, chlorinated hydrocarbons such as TCBP and HCB are known to strongly resist metabolic breakdown (Schwarzenbach et al. 1993). Furthermore, minimal radioactivity was detected in feeding chambers at the end of the depuration period, and experiments were kept short (usually $<24 \mathrm{~h}$ ), so that excretion and degradation were probably minimal. We therefore believe that the AEs measured as described approximated quite well the percentage of HOC ultimately absorbed by the worms.

In a previous experiment, using the identical sediment used 430 d later for this study, Nereis succinea absorbed freshly spiked TCBP and HCB, with AEs of roughly $90 \%$ (Ahrens et al. unpubl. data), compared to $73 \%$ for the same sediments after $430 \mathrm{~d}$ of aging. Over $14 \mathrm{mo}$, AEs had therefore decreased by approx. 15 to $20 \%$ for both HOCs. These results suggest that although sediment aging tends to decrease bioavailability, the majority of HOC remains bioavailable to $N$. succinea. This contrasts with several studies (predominantly on microorganisms) that demonstrated a substantial reduction of HOC bioavailability with increasing sediment age (review by Loehr \& Webster 1996, but see also Landrum et al. 1992). One explanation for this discrepancy might be the characteristically strong surfactancy and high protein concentrations of depositfeeder gut fluids, which might be able to solubilize aged HOC fractions that are not bioaccessible to sediment/soil microorganisms. It should be remembered, however, that we conducted our experiments with artificially amended sediment. Thus, even though we aged our sediment for $430 \mathrm{~d}$ (so as to approximate field conditions more closely), contaminant availability from this artificially labeled (originally pristine) sediment may have been very different from conventionally con- 
taminated sediments. Therefore, we agree with Weston \& Mayer (1998a) that caution is advised when extrapolating conclusions about desorbability from experiments using spiked sediments in order to estimate in situ availability.

Despite significant differences in octanol-water partitioning coefficients $\left(\log K_{\text {ow }}[\mathrm{TCBP}]=6.31\right.$ and $\log K_{\mathrm{ow}}$ $[\mathrm{HCB}]=5.50$ ), both compounds were absorbed to the same degree by Nereis succinea, a finding which was replicated in several other experiments by us (Ahrens et al. unpubl. data). Analogously, TCBP and HCB desorbed with almost identical efficiencies during in vitro gut fluid incubations, and the amount of HOCs solubilized by gut fluids after 360 min closely matched AEs of organisms. A close relationship between in vitro gut fluid solubilization and AE was also found for PAHs by Weston \& Mayer (1998a,b) for Arenicola marina. Our work corroborates their hypothesis that digestive solubilization is a critical prerequisite for HOC bioavailability and is likely to set an upper limit on absorption. Our finding that TCBP and HCB were absorbed with equal (high) efficiencies, despite differing hydrophobicities $\left(\log K_{\text {ow }}\right)$ suggests that absorption by worm tissues might have occurred directly via incorporation of contaminant-loaded micellar phases rather than via the aqueous phase, which has also been proposed by Guha \& Jaffé (1996), and Guha et al. (1998) for microorganisms. Similarly, the 'dissolved' phase in our desorption experiments may actually have been a combination of truly dissolved and micellar phases, which were not separated by the centrifugation process. The short centrifugation time $(60 \mathrm{~s}$ at $1600 \times g)$ chosen to separate the dissolved from the particulate fraction was necessary to allow sampling with high frequency. In all cases, the overlying fraction after centrifugation was clear and visually particle-free. Nonetheless, this does not preclude the presence of micro-emulsions of HOC, surfactant micelles or very small particles, invisible to the naked eye. The maximum error incurred by resuspension of particulates during the pipette removal step was estimated to be $5 \%$ (i.e. the desorption efficiency of $150 \mu$ filtered seawater over a $360 \mathrm{~min}$ extraction period), and was probably much lower.

Desorption by gut fluids proceeded very rapidly, mobilizing over two-thirds of the bioavailable fraction (defined here as the amount of HOC desorbed in $360 \mathrm{~min}$ ) within the first minute of contact. The apparent log-linear relationship between DE and extraction time (volume), regardless of whether sediment was extracted in 1 or repetitive extractions, suggests the presence of a reversibly adsorbed HOC phase that is quickly accessible to digestive surfactants. If desorption is the primary requisite for absorption, this may explain the observation that juvenile worms, which have gutpassage times (GPT) more than 1 order of magnitude shorter than adult worms, can still have very high absorption efficiencies for HOCs. For example, juvenile Nereis succinea (GPT: 30 to $60 \mathrm{~min}$ ) have average AEs of 70 to $75 \%$ for TCBP and HCB, whereas adult worms (GPT: $>5$ h) have AEs around $90 \%$, when fed freshly spiked sediments (Ahrens et al. unpubl. data).

The solid/fluid ratio of $0.1 \mathrm{~g} \mathrm{ml}^{-1}$ used in the desorption experiment (1-time $150 \mu \mathrm{l}$ addition) was several times lower than the solid/fluid ratios measured in gut contents of Nereis succinea and Pectinaria gouldii (0.5 to $0.6 \mathrm{~g} \mathrm{ml}^{-1}$ : Table 1). Plante \& Mayer (1994) similarly reported higher solid/fluid ratios of 0.2 to $0.8 \mathrm{~g}$ $\mathrm{ml}^{-1}$ for gut contents of Arenicola marina and Amphitrite johnstoni, and Weston \& Mayer (1998b) employed solid/fluid ratios of 0.4 to $0.5 \mathrm{~g} \mathrm{ml}^{-1}$ in their PAH desorption studies. Desorption efficiencies determined in the 1-time $150 \mu$ addition experiment are thus likely to represent an upper limit to solubilization, or 'potential bioavailability'. In contrast, our repetitive addition experiment, employing a solid/fluid ratio of $1 \mathrm{~g} \mathrm{ml}^{-1}$, was conducted at slightly more concentrated conditions than those typical for deposit-feeder guts. Using terminology from reactor theory (Penry \& Jumars 1987), our 1-time addition experiment functionally represented a constantly stirred reactor (CTSR), whereas the repetitive addition experiment represented a plug flow reactor (PFR), in which sediment was subjected to a sequence of digestions. Comparison of HOC solubilization between the 1-time addition and the repetitive addition experiment showed that desorption efficiency differed the most for the initial (1 min) time point of solubilization (i.e. when extraction volumes differed most), while the percentage of HOC solubilized matched increasingly well with increasing extraction time (and converging total extraction volume). In other words, the performance of a PFR quickly approximates a CSTR within several iterations, if desorption products are removed and fresh extractant replenished, as was the case in our experiment.

Voparil \& Mayer (2000) recently compared PAH solubilization over a range of solid/fluid ratios (0.015 to $1 \mathrm{~g} \mathrm{ml}^{-1}$ ) and found the absolute amount of solubilized $\mathrm{PAH}$ to level off (and in some cases even to decrease) with higher solid/fluid ratios. To explain the diminished solubilization at high solid/fluid ratios, they proposed possible saturation of the hydrophobic phase and/or competition for micellar space by other sedimentary lipids. Nonetheless, on a relative scale, low solid/fluid ratios solubilized a greater percentage of total HOC, which is identical to our findings. The good agreement between our absorption efficiencies and in vitro gut fluid desorption efficiencies, despite 2- to 6 -fold differences between in vitro and in vivo solid/ fluid ratios, suggests that total gut fluid volume in deposit feeders is sufficiently large so that the 
solid/fluid ratio does not limit HOC bioavailability on typical digestive time or spatial scales. Similar conclusions were also reached by Hamel et al. (1998) for metal solubilization from soils by synthetic gastric juice, where changes in solid/fluid ratios had little effect on metal bioavailability.

A possible caveat of our desorption efficiency methodology was the rinsing step at the end of the incubation period. Flushing sediments with $500 \mu$ l seawater (to retrieve gut fluid trapped in pore spaces) may have caused dissolution of surfactant micelles, potentially leading to re-adsorption of previously micelle-solubilized HOC back onto sediment particles. In the case of the 1-time addition experiments (involving $150 \mu \mathrm{l}$ of gut fluid) this 3-fold dilution may not have had a severe impact, considering that CMD of the gut fluids used was 10 to $40 \%$. In contrast, in the repetitive addition experiment (where only $15 \mu \mathrm{l}$ of gut fluid were rinsed with $500 \mu$ l seawater), TCBP-loaded micelles may have completely dissolved upon dilution, resulting in lowered solubilization capacity. It is possible that the surfactancy decrease resulting from dilution was offset by the increased effective extraction volume and thus not noticeable. On the other hand, it is also conceivable that HOCs, once solubilized, will stay in solution regardless of micelle presence, as long as surface tension is low.

The high absorption efficiencies by worms could be achieved in 2 ways: either worms rapidly absorb all desorbed compounds, and thereby maintain a steep concentration gradient between gut fluid and sediment, or they have surfactant concentrations large enough to keep dissolved HOCs from saturating in the gut fluid. The strong surfactancy and high DOM concentrations found in deposit-feeder guts support the second hypothesis. A third alternative for achieving high desorption efficiencies, namely by having sufficiently long sediment-retention times, seems unlikely in the light of recent evidence that juvenile deposit feeders, who have short sediment-residence times, have very similar AEs to adults (Ahrens unpubl. data). From a nutritional standpoint, a digestive strategy relying on the rapid desorption of organic matter from transiting particulate material and a long retention time for solubilized material in the gut fits well with the feeding style demonstrated by deposit feeders. The fact that this digestive strategy not only maximizes food uptake but also elevates bioavailability of ingested organic contaminants is an unfortunate side-effect for the organism.

\section{CONCLUSIONS}

Desorption efficiencies (DE) of gut fluids for 2 hydrophobic organic contaminants (HOC) closely matched absorption efficiencies (AE) determined in live organisms. Nereis (Neanthes) succinea solubilized and absorbed about twice as much TCBP and HCB as Pectinaria (Cistenides) gouldii, which correlated with greater surfactancy of $N$. succinea's gut fluid. It thus appears that digestive solubilization, to a large extent accomplished by intestinal surfactants, is the primary control and predictor of AE for the 2 HOCs tested. Although not investigated by us, digestive enzymes, amino acids and other DOM may further enhance the solubilizing properties of gut fluids. The observation that HOC desorption proceeded very rapidly suggests that gut-residence time exerts only a minor influence on HOC bioavailability. It furthermore suggests the presence of a rapidly exchangeable, bioavailable pool of HOCs, perhaps in the form of surface coatings that can be efficiently removed by surfactants. Since we have practically no information on the chemical structure and functional mechanism of invertebrate surfactants, a systematic characterization of the digestive surfactants of different animal taxa would be a very promising topic for further research. One potential application of such studies could be the formulation of a synthetic 'gut juice cocktail', which could be used as a quick-screening tool to assess HOC bioavailability from contaminated sediments before conducting timeconsuming uptake experiments. Such a procedure could supersede existing extraction protocols that employ less biologically relevant solvents. However, the search for a single extractant to universally predict bioavailability may be conceptually flawed in the light of our present (and other) findings that species-specific differences in digestion play a major role in controlling organic contaminant availability. Perhaps by employing different dilutions of a suitable extractant, relevant upper and lower limits of HOC bioavailability can be determined for a given sediment. The close correlation between HOC solubilization and absorption in polychaetes resembles observations by Gagnon \& Fisher (1997) for trace metal uptake in bivalves, where desorbability similarly correlated with AE (however only for organic matter-coated particles). In the case of trace metals, solubilization is presumably not brought about by intestinal surfactants, but rather by other properties of the gut fluid (e.g. pH, redox or DOM), and correlations between desorption and absorption are generally weaker. Future studies should therefore move beyond empirical correlations and focus on the mechanisms of contaminant solubilization by gut fluids, as well as on the subsequent absorption by the organism.

Acknowledgements. We would like to thank A. Larson and N. Maher for help with collecting worms, and D. Hirschberg and the Analytical Services Facility of the Marine Sciences Research Center for conducting the $\mathrm{CN}$ analysis. Comments by L. Mayer and 4 anonymous reviewers greatly improved 
the manuscript. Grant 003-96-A from Hudson River Foundation and grant OCE 9711793 from NSF funded this work. This is contribution 1213 from the Marine Sciences Research Center.

\section{LITERATURE CITED}

Cammen LM (1980) Ingestion rate: an empirical model for aquatic deposit feeders and detritivores. Oecologia 44: 303-310

DiToro DM, Zarba CS, Hansen DJ, Berry WJ, Swartz RC, Cowan CE, Pavlou SP, Allen HE, Thomas NA, Paquin PR (1991) Technical basis for estimating sediment quality criteria for nonionic organic chemicals using equilibrium partitioning. Environ Toxicol Chem 10:1541-1583

Fauchald K, Jumars PA (1979) The diet of worms: a study of polychaete feeding guilds. Oceanogr Mar Biol Annu Rev 17:193-284

Gagnon C, Fisher NS (1997) The bioavailability of sedimentbound $\mathrm{Cd}$, Co and Ag to the mussel Mytilus edulis. Can J Fish Aquat Sci 54:147-156

Guha S, Jaffé PR (1996) Bioavailability of hydrophobic compounds partitioned into the micellar phase of nonionic surfactants. Environ Sci Technol Libr 30:1382-1391

Guha S, Jaffé PR, Peters CA (1998) Bioavailability of mixtures of PAHs partitioned into the micellar phase of a nonionic surfactant. Environ Sci Technol Libr 32:217-2324

Hamel SC, Buckley B, Lioy PJ (1998) Bioaccessibility of metals in soils for different liquid to solid ratios in synthetic gastric fluid. Environ Sci Technol Libr 32:358-362

Jumars PA, Mayer LM, Deming JW, Baross JA, Wheatcroft RA (1990) Deep-sea deposit-feeding strategies suggested by environmental and feeding constraints. Phil Trans R Soc Lond A Math Phys Sci 331(1616):85-101

Landrum PF, Eadie BJ, Faust WR (1992) Variation in the bioavailability of polycyclic aromatic hydrocarbons to the amphipod, Diporeia spp., with sediment aging. Environ Toxicol Chem Libr 11:1197-1208

Loehr RC, Webster MT (1996) Behavior of fresh vs. aged chemicals in soils. J Soil Contam 5:361-383

Lopez GR, Cheng IJ (1983) Synoptic measurements of ingestion rate, ingestion selectivity, and absorption efficiency of natural foods in the deposit-feeding mollusks Nucula annulata (bivalvia) and Hydrobia totteni (gastropoda). Mar Ecol Prog Ser 11:55-62

Luoma SN, Johns C, Fisher NS, Steinberg NS, Oremland RS, Reinfelder JR (1992) Determination of selenium bioavailability to a benthic bivalve from particulate and solute pathways. Environ Sci Technol Libr 26:485-491

Mayer LM, Macko SA, Cammen L (1988) Provenance, concentrations and nature of sedimentary organic nitrogen in the Gulf of Maine. Mar Chem 25:291-304

Mayer LM, Chen Z, Findlay RH, Fang J, Sampson S, Self RFL, Jumars PA, Quetél C, Donard OFX (1996) Bioavailability of sedimentary contaminants subject to deposit-feeder digestion. Environ Sci Technol Libr 30:2641-2645

Mayer LM, Schick LL, Self RFL, Jumars PA, Findlay RH, Chen Z, Sampson S (1997) Digestive environments of benthic macroinvertebrate guts: enzymes, surfactants and dis- solved organic matter. J Mar Res 55:785-812

McElroy AE, Means JC (1988) Factors affecting the bioavailability of hexachlorobiphenyls to benthic organisms. In: Adams WJ, Chapman GA, Landis WG (eds) Aquatic toxilogy and hazard assessment: 10th Volume, ASTM STP 971. American Society for Testing and Materials, Philadelphia, p 149-158

McGroddy SE, Farrington JW, Gschwend PM (1996) Comparison of the in situ and desorption sediment-water partitioning of polycyclic hydrocarbons and polychlorinated biphenyls. Environ Sci Technol Libr 30(1):172-177

Montluçon D (1997) Mechanisms controlling adsorption capacity of Flax Pond sediments. MS thesis, Marine Sciences Research Center, State University of New York, Stony Brook

Penry DL (1998) Applications of efficiency measurements in bioaccumulation studies: definitions, clarifications and a critique of methods. Environ Toxicol Chem 17:1633-1639

Penry DL, Jumars PA (1987) Modeling animal guts as chemical reactors. Am Nat 129:69-96

Plante CJ, Mayer LM (1994) Distribution of bacteriolysis in the gut of Arenicola marina and three additional deposit feeders. Mar Ecol Prog Ser 109:183-194

Reinfelder JR, Fisher NS (1991) The assimilation of elements ingested by marine copepods. Science 251:794-796

Schwarzenbach RP, Gschwend PM, Imboden DM (1993) Environmental organic chemistry. Wiley \& Sons, New York

Standley LJ (1997) Effect of sedimentary organic matter composition on the partitioning and bioavailability of dieldrin to the oligochaete Lumbriculus variegatus. Environ Sci Technol Libr 31:2577-2583

Vonk HJ (1969) The properties of some emulsifiers in the digestive fluids of invertebrates. Comp Biochem Physiol 29:361-371

Voparil IM, Mayer LM (2000) Dissolution of sedimentary polycyclic aromatic hydrocarbons (PAHs) into the lugworm's (Arenicola marina) digestive fluid. Environ Sci Technol Libr 34:1221-1228

Wang WX, Fisher NS (1999) Assimilation efficiencies of chemical contaminants in aquatic invertebrates: a synthesis. Environ Toxicol Chem 18:2034-2045

Wang WX, Stupakoff I, Fisher NS (1999) Bioavailability of dissolved and sediment-bound metals to a marine depositfeeding polychaete. Mar Ecol Prog Ser 178:281-293

Weston DP, Mayer LM (1998a) In vitro digestive fluid extraction as a measure of the bioavailability of sediment-associated polycyclic aromatic hydrocarbons: sources of variation and implications for partitioning models. Environ Toxicol Chem 17(5):820-829

Weston DP, Mayer LM (1998b) Comparison of in vitro digestive fluid extraction and traditional in vivo approaches as measures of polycyclic aromatic hydrocarbon bioavailability from sediments. Environ Toxicol Chem 17:830-840

Whitlatch RB, Weinberg JR (1982) Factors influencing particle selection and feeding rate in the polychaete Cistenides (Pectinaria) gouldii. Mar Biol 71:33-40

Yamamoto N, Lopez GR (1985) Bacterial abundance in relation to surface area and organic content in marine sediments. J Exp Mar Biol Ecol 90:209-220

Submitted: January 24, 2000; Accepted: August 8, 2000 Proofs received from author(s): February 6, 2001 